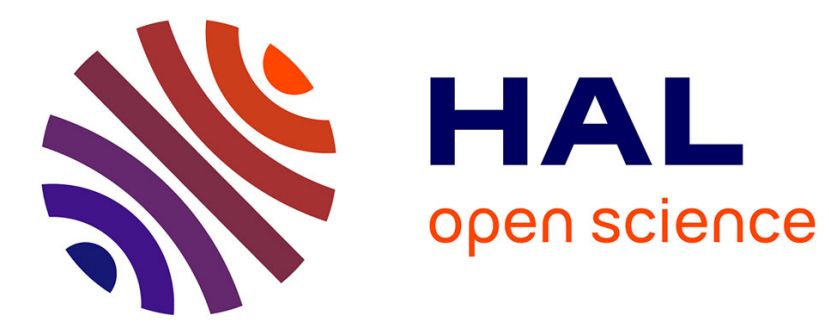

\title{
The new ALEPH Silicon Vertex Detector
}

\author{
D. Creanza, M. de Palma, G. Maggi, G. Selvaggi, L. Silvestris, G. Raso, P. \\ Tempesta, M. Burns, P. Coyle, M. Frank, et al.
}

\section{To cite this version:}

D. Creanza, M. de Palma, G. Maggi, G. Selvaggi, L. Silvestris, et al.. The new ALEPH Silicon Vertex Detector. The 7th Pisa Meeting on Advanced Detectors, May 1997, La Biodola, Isola D'Elba, Italy. pp.157-160. in2p3-00012092

\section{HAL Id: in2p3-00012092 https://hal.in2p3.fr/in2p3-00012092}

Submitted on 22 Mar 1999

HAL is a multi-disciplinary open access archive for the deposit and dissemination of scientific research documents, whether they are published or not. The documents may come from teaching and research institutions in France or abroad, or from public or private research centers.
L'archive ouverte pluridisciplinaire HAL, est destinée au dépôt et à la diffusion de documents scientifiques de niveau recherche, publiés ou non, émanant des établissements d'enseignement et de recherche français ou étrangers, des laboratoires publics ou privés. 


\title{
The new ALEPH Silicon Vertex Detector
}

D. Creanza ${ }^{a}$, M. de Palma ${ }^{a}$, G. Maggi ${ }^{a}$, G. Selvaggi ${ }^{a}$, L. Silvestris ${ }^{a}$, G. Raso ${ }^{a}$,

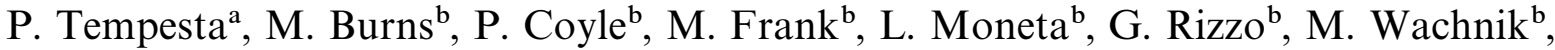
A. Wagner ${ }^{\mathrm{b}}$, E. Focardi ${ }^{\mathrm{c}, *}$, G. Parrini $^{\mathrm{c}}$, E. Scarlini ${ }^{\mathrm{c}}$, A. Halley ${ }^{\mathrm{d}}$, V. O’Shea ${ }^{\mathrm{d}}$, C. Raine ${ }^{\mathrm{d}}$, G. Barbere ${ }^{\mathrm{e}}$, W. Cameron ${ }^{\mathrm{e}}$, P. Dornan ${ }^{\mathrm{e}}$, D. Gentry ${ }^{\mathrm{e}}$, N. Konstantinidis ${ }^{\mathrm{e}}$, A. Moutoussi ${ }^{\mathrm{e}}$, J. Nash ${ }^{\mathrm{e}}$, D. Price ${ }^{\mathrm{e}}$, A. Stacey ${ }^{\mathrm{e}}$, L.W. Toudup ${ }^{\mathrm{e}}$, M.I. Williams ${ }^{\mathrm{f}}$, M. Billault ${ }^{\mathrm{g}}$, A. Bonissent $^{\mathrm{g}}$, G. Bujosa ${ }^{\mathrm{g}}$, D. Calvet ${ }^{\mathrm{g}}$, J. Carr ${ }^{\mathrm{g}}$, C. Diaconu ${ }^{\mathrm{g}}$, P.E. Blanc ${ }^{\mathrm{g}}$, J.J. Destelle ${ }^{\mathrm{g}}$, P. Karst ${ }^{\mathrm{g}}$, P. Payre ${ }^{\mathrm{g}}$, D. Rousseau ${ }^{\mathrm{g}}$, M. Thulasidas ${ }^{\mathrm{g}}$, H. Dietl ${ }^{\mathrm{h}}$, H.G. Moser ${ }^{\mathrm{h}}$, R. Settles ${ }^{\mathrm{h}}$, H. Seywerd ${ }^{\mathrm{h}}$, G. Waltermann ${ }^{\mathrm{h}}$, F. Bosi ${ }^{\mathrm{i}}$, C. Bozzi ${ }^{\mathrm{i}}$, R. Dell'Orso ${ }^{\mathrm{i}}$, A. Profeti ${ }^{\mathrm{i}}$, G. Sguazzoni ${ }^{\mathrm{i}}$, P.G. Verdini, J.P. Bizzell ${ }^{j}$, P.D. Maley ${ }^{j}$, J.C. Thompson ${ }^{j}$, A.E. Wright ${ }^{\mathrm{j}}$, S. Black ${ }^{\mathrm{k}}$, J. Dann ${ }^{\mathrm{k}}$, H.Y. Kim ${ }^{\mathrm{k}}$, L. Bosisio, J. Putz ${ }^{\mathrm{m}}$, J. Rothberg ${ }^{\mathrm{m}}$, S. Wasserbaech ${ }^{\mathrm{m}}$, P. Elmer ${ }^{\mathrm{n}}$, J. Walsh ${ }^{\mathrm{n}}$

${ }^{a}$ Dip. di Fisica, INFN Sezione di Bari, 70126 Bari, Italy

${ }^{\mathrm{b}}$ European Laboratory for Particle Physics (CERN), CH 1211 Geneva 23, Switzerland

${ }^{\mathrm{c}}$ Dip. di Fisica dell'Università e INFN Sezione di Firenze, 50125 Firenze, Italy

${ }^{\mathrm{d}}$ Dept. of Physics and Astronomy, University of Glasgow, Glasgow G12 8QQ, UK

${ }^{\mathrm{e}}$ Dept. of Physics, Imperial College, London SW7 2BZ, UK

${ }^{\mathrm{f}}$ Dept. of Physics, University of Lancaster, Lancaster LA1 4YB, UK

${ }^{\mathrm{g}}$ Centre de Physique des Particules, Faculté des Sciences de Luminy, IN2P3-CNRS, 13288 Marseille, France

${ }^{\mathrm{h}}$ Max-Planck-Institut für Physik, Werner-Heisenberg-Institut, 80805 München, Germany

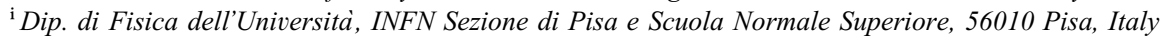

j Particle Physics Dept., Rutherford Appleton Laboratory, Chilton, Didcot, Oxon OX11 OQX, UK

${ }^{\mathrm{k}}$ Institute for Particle Physics, University of California at Santa Cruz, Santa Cruz, CA 95064, USA

${ }^{1}$ Dip. di Fisica dell'Universitàe INFN Sezione di Trieste, 34127 Trieste, Italy

${ }^{\mathrm{m}}$ Experimental Elementary Particle Physics, University of Washington, WA 98195 Seattle, USA

${ }^{\mathrm{n}}$ Dept. of Physics, University of Wisconsin, Madison, WI 53706, USA

\begin{abstract}
The ALEPH collaboration, in view of the importance of effective vertex detection for the Higgs boson search at LEP 2, decided to upgrade the previous vertex detector. Main changes were an increased length $( \pm 20 \mathrm{~cm})$, a higher granularity for $r \phi$ view $(50 \mu \mathrm{m})$, a new preamplifier (MX7 rad hard chip), a polymide (upilex) fan-out on $z$ side to carry the signals from the strips to the front-end electronics outside the fiducial region reducing consequently the passive material in the central region by a factor of two. The detector, the running experience and its performance will be described. (C) 1998 Elsevier Science B.V. All rights reserved.
\end{abstract}

* Corresponding author. 


\section{Introduction}

The extensive study of the heavy flavour physics currently under way in the present generation of colliders made the Silicon Vertex Detectors the key tool to identify particles with heavy quarks $(b, c)$. Tracks with the impact parameters in the $100 \mu \mathrm{m}$ range are identified with high accuracy when extrapolated to the interaction point. Secondary vertices few $\mathrm{mm}$ apart from the interaction point are clearly distinguished. For an accurate track reconstruction in space it was decided to use double-sided silicon strip detectors arranged in a cylindrical two-layer detector with a coverage of $|\cos \theta|<0.85$ for tracks to pass through at least the inner layer. The detector (VDET I) worked as expected during the LEP1 phase from 1991 until 1995.

The Higgs boson search at LEP2 increased the importance of effective vertex detection. The Aleph collaboration consequently decided to upgrade the previously installed VDET. Main features of the new vertex detector are

1. increased length $( \pm 20 \mathrm{~cm}), 6$ detectors/face are used;

2. a polymide (upilex) fan-out is used on the $z$-side to carry the signals from the strips to the front-end electronics outside the active region; in this way the passive material is reduced by a factor of two;

3. the preamplifier chip used now is MX7 radiation hard;

4. the strip read-out pitch is $50 \mu \mathrm{m}$ for $r-\phi$ view and $100 \mu \mathrm{m}$ for the $z$ view.

For an overall description of VDET I and a comparison between VDET I and VDET II, see Ref. [2].

\section{Detector description}

VDET II consists of 48 modules glued in 24 faces (Fig. 1) mounted in two concentric layers. The inner layer with 9 faces is located at an average radius of $6.3 \mathrm{~cm}$ while the outer layer with 15 faces is at a radius of $11 \mathrm{~cm}$. Fig. 2 shows an overall view of the detector. Each module has three double-sided silicon strip detectors with dimensions $6.4 \times 5.3 \mathrm{~cm}^{2}$ each, the thickness is $300 \mu \mathrm{m}$. The design of the

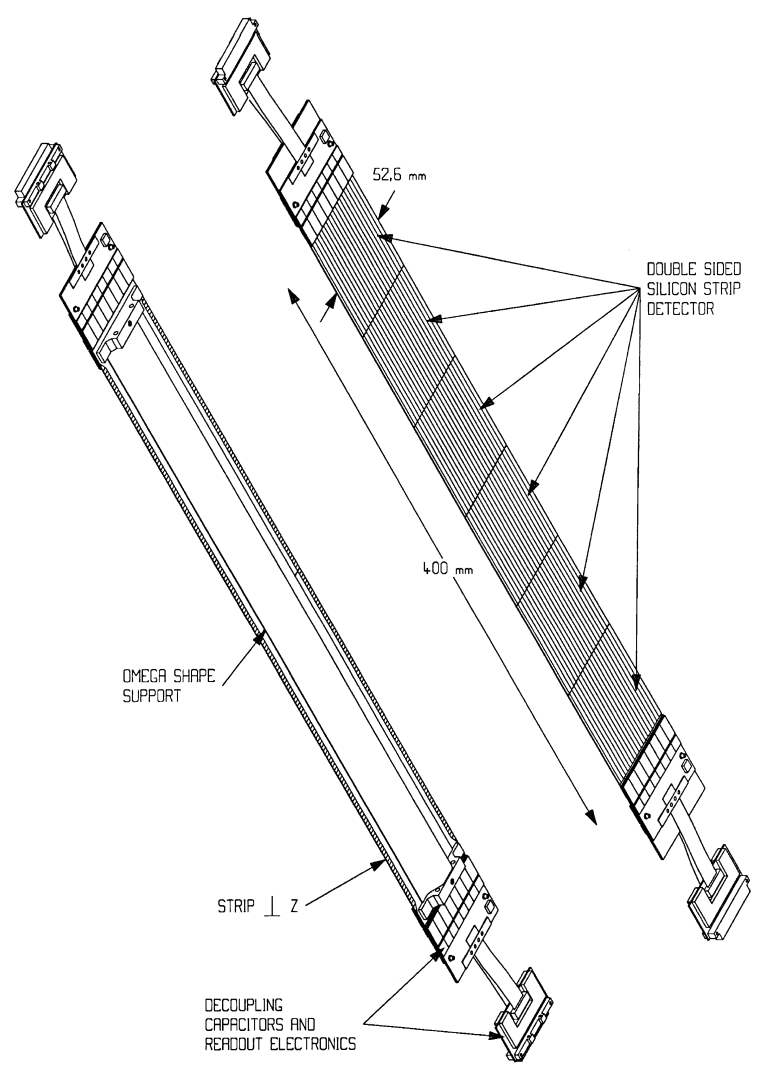

Fig. 1. VDET face.

silicon detectors is similar to the one used for VDET I [1] with strip pitch of $25 \mu \mathrm{m}$ on the junction side $(r-\phi$ view $)$ and $50 \mu \mathrm{m}$ on the ohmic side $(z$ view). Implanted $\mathrm{p}^{+}$strips between the $\mathrm{n}^{+}$strips on the ohmic side are used to block the electron accumulation layer present at the $\mathrm{Si}-\mathrm{SiO}_{2}$ interface. Guard rings surrounding the active region is used to bias the strips; on the junction side the punchtrough mechanism is used to provide the bias with the $\mathrm{p}^{+}$strips ending a few microns from the guard ring implant. On the ohmic side $\mathrm{n}^{+}$strips are biased taking advantage of the electron accumulation layer: the end of $\mathrm{p}^{+}$blocking strips is used to define a channel between the $\mathrm{n}^{+}$strips and the guard ring; the value of the bias resistor, determined by the length and the width of this low resistivity layer ( $\sim 30 \mathrm{k} \Omega$ per square), is $R_{s-g r}=12-20 \mathrm{M} \Omega$. The detectors are operated at a voltage slightly above the depletion value. One end of each module is 


\section{ALEPH SILICON VERTEX DETECTOR}

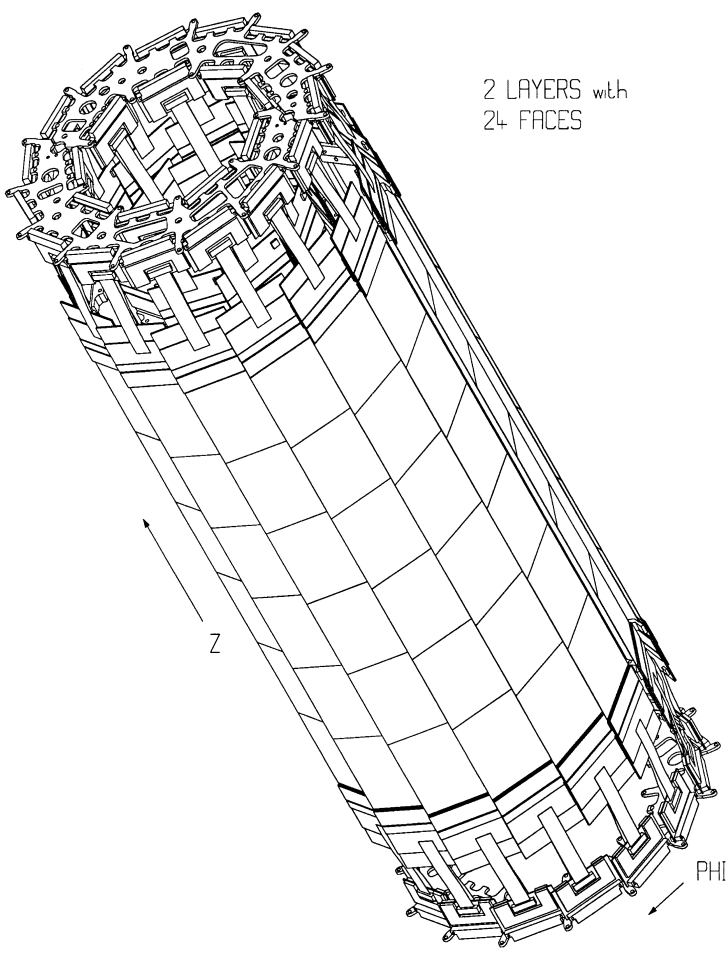

Fig. 2. VDET overall view. equipped with two electronic hybrids, one for the $z$ view and the other for the $r-\phi$ view. Each hybrid has eight radiation hard MX7 chip and associated decoupling capacitors with protection diodes. Each MX7 chip shifts out the signals from 128 strip channels and the 1024 channels of each view are output sequentially (every $2 \mu$ s) onto a single analog data line. Electronic chips are cooled with a gravity fed water distribution system and air flow is used to reduce temperature gradients along the detector. The total power dissipation is about $200 \mathrm{~W}$. In the $r-\phi$ view 1021 strips are read-out while in the $z$ view 960 strips are read-out with a total of 95088 for the complete detector. Table 1 summarizes the basic properties of the detectors.

\section{Performance}

The complete detector was installed in Aleph during the spring 1996; 16000 hadronic $Z^{0}$ decays were collected at the start of the run in July'96. These data have been used to study the performance of the detector; the signal/noise measured after the installation was similar to that obtained in the laboratory (Fig. 3). The face distortion problem found during the previous run in Novem-

Table 1

Properties of the ALEPH Silicon Detectors

Detector dimensions

Wafer thickness

Bulk resistivity

Depletion voltage
$52.6 \mathrm{~mm} \times 65.4 \mathrm{~mm}$

$300 \mu \mathrm{m}$

$6-30 \mathrm{k} \Omega \mathrm{cm}$

20-62 V
Junction side, $r \phi$-side

$51.0 \mathrm{~mm} \times 63.92 \mathrm{~mm}$

Active area

p-strips (diodes)

p-blocking strips

n-strips

(p/n) pitch

Strip length

Strip width

Readout pitch

Bond pad size
2041

$-$

$-$

$25 \mu \mathrm{m}$

$63.92 \mathrm{~mm}$

$12 \mu \mathrm{m}$

$50 \mu \mathrm{m}$

$300 \mu \mathrm{m} \times 50 \mu \mathrm{m}$
Ohmic side, $z$-side

$49.68 \mathrm{~mm} \times 63.90 \mathrm{~mm}$

1280

1279

$50 \mu \mathrm{m}$

$49.68 \mathrm{~mm}$

$12 \mu \mathrm{m}$

$100 \mu \mathrm{m}$

$300 \mu \mathrm{m} \times 50 \mu \mathrm{m}$ 


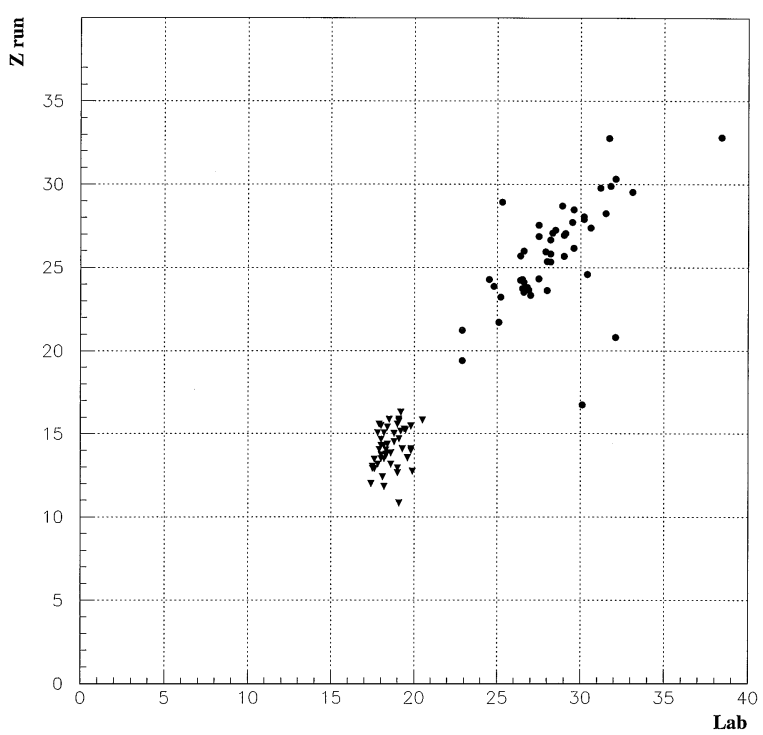

Fig. 3. Comparison of signal to noise ratio from laboratory measurements with that from $Z^{0}$ run data (June '96). Points are plotted for all 48 VDET II modules: triangles for $z$ view and circles for the $r-\phi$ view.

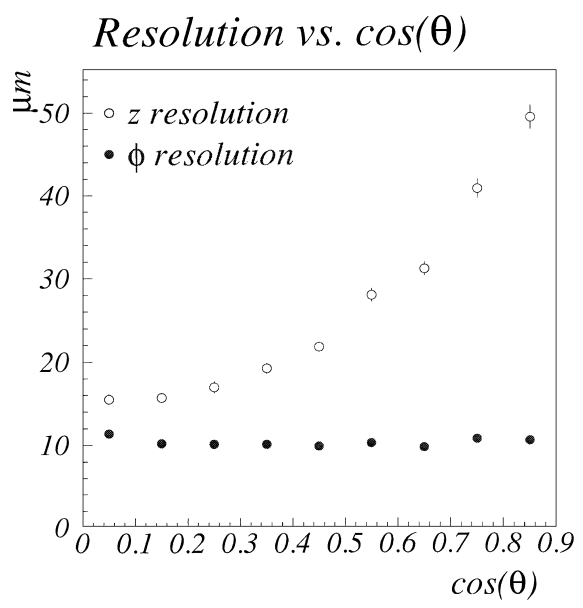

Fig. 4. VDET resolution measured from tracks with three hits in the overlaps.

ber '95 [2], was solved by reinforcing the kevlar support that holds the two modules in a face with a similar carbon fibre omega beam support glued on top of the kevlar one. The distortions as measured by a laser position monitoring system [3] are now below $5 \mu \mathrm{m}$. $Z^{0}$ data have been used to align
Table 2

Summary of VDET II performance

\begin{tabular}{lcc}
\hline & $z$ side & $r-\phi$ side \\
\hline Physical strip pitch & $50 \mu \mathrm{m}$ & $25 \mu \mathrm{m}$ \\
Number of physical strips per wafer & 1279 & 2041 \\
Readout strip pitch & $100 \mu \mathrm{m}$ & $50 \mu \mathrm{m}$ \\
Number of readout strips per wafer & 640 & 1021 \\
Number of readout strips per module & 960 & 1021 \\
Signal/noise $\left(90^{\circ}\right)$ & 18 & 31 \\
Resolution $\left(90^{\circ}\right)$ & $15 \mu \mathrm{m}$ & $10 \mu \mathrm{m}$ \\
\hline
\end{tabular}

the detector. An alignment precision better than the intrinsic resolution of the detector itself was reached by using the measurements of the wafer relative positions within a face done after fabrication and constraining tracks, in events without secondary vertices, to come from the same primary vertex. The resolution is measured from tracks passing through the overlap regions where two hits are used to predict the position of the third hit. The resolution as a function of $\cos \theta$ is shown in Fig. 4. The average efficiency to find a cluster on one side when a cluster is found on the other side is $95 \%$ for $r-\phi$ view and $93 \%$ for $z$ view. The performance of VDET II is summarized in Table 2.

\section{Conclusion}

A new Silicon Vertex Detector has been installed in ALEPH for LEP2 operations. The discovery potential for the Higgs search has been increased by extending the angular coverage and by reducing the material in the tracking volume. In the $r-\phi$ view the granularity has been increased by using $50 \mu \mathrm{m}$ read-out strip pitch. The device is performing as expected with a mechanical stability better than $5 \mu \mathrm{m}$. The spatial resolution obtained is $10 \mu \mathrm{m}$ on the $r-\phi$ side and $15 \mu \mathrm{m}$ on the $z$ side.

\section{References}

[1] B. Mours et al., Nucl. Instr. and Meth. A 379 (1996) 101.

[2] E. Focardi, Nucl. Instr. and Meth. A 386 (1997) 18.

[3] A. Wagner, The laser calibration system for VDET II, ALEPH 97-006 MINIV 97-001, 1997. 